\title{
Of lion manes and human beards: some unusual effects of the interaction between aggression and sociality
}

\author{
D. Caroline Blanchard ${ }^{1,2 *}$ \\ Pacific Biosciences Center, University of Hawaii at Manoa, Honolulu, HI, USA \\ 'Department of Cellular and Molecular Biology, John A. Burns School of Medicine, Honolulu, HI, USA
}

Edited by:

Guillaume Poirier, Ecole Polytechnique Fédérale de Lausanne, Switzerland

\section{Reviewed by:}

Jaap Koolhaas,

University of Groningen,

The Netherlands

Carmen Sandi, Ecole Polytechnique

Fédérale De Lausanne, Switzerland

\section{*Correspondence.}

D. Caroline Blanchard, 1993 East West

Road, Honolulu, HI 96822, USA.

e-mail: blanchar@hawaii.edu
The function of manes in lions has been a topic of scientific interest since Darwin (1871) suggested that it provides protection in intraspecific fights. Recent experimental studies on wild lions have emphasized the role of female selection, but analyses of specific attack behaviors and targets, and the social consequences of manelessness for lions living in very hot climates suggest that male manes may indeed mitigate the outcomes of intraspecific male attack and thus serve a permissive function for multi-male + female groups, facilitating protection of prides against take-overs and infanticide by nomadic males. Humans also have unusual structural protections for the head, face and neck, areas that are especially accessible during intraspecies attack, and highly vulnerable to damage. One of these, the beard, consists of coarse hairs that grow indefinitely, but only for males, and only during and following puberty; suggesting that it, like the lion's mane, may serve as protection in intraspecies male fights. Such structural protections may reflect a specific combination of lethal weaponry and social life-style, particularly when these are developed so rapidly that they are not accompanied by the evolution of complex attack-inhibiting social behaviors.

Keywords: lion, mane, beard, aggression, social systems, target sites, infanticide, evolution
Lion manes are obviously a sexually selected trait. Manes are restricted to males, contribute little to the lion's general economy of life, and apparently present a number of real costs that would otherwise make it a candidate for elimination by natural selection..... Still, given the interest that people have focused on lions over the last 30,000 years, it is remarkable that we do not know whether manes are the product of male-male contest, or female choice, or possibly of both

(Patterson, 2004, p. 141).

\section{AGGRESSION, SOCIAL SYSTEMS AND EVOLUTION}

In terms of phylogeny, aggression is among the oldest of evolved behavior patterns (Blanchard and Blanchard, in press). Exemplars of aggression have been reported in animals without a central nervous system; in a host of invertebrates; and in each of the seven classes of vertebrates, including the most primitive; agnatha, hagfish and lampreys (Malmqvist, 1983). There is an emerging consensus that one major function, i.e. adaptive consequence, of aggression, across animal species, is resource control (e.g. Wilson, 1971), with the further provision that aggression typically occurs in the context of competition from conspecifics over such resources. Winning may be highly adaptive because it results in immediate or longer-term enhancement of access to resources that are important for that species (Blanchard and Blanchard, 1984; Moynihan, 1998).

Resources and their distribution are also major factors in the development of species-typical social systems (Rubenstein, 2009), of which within-species aggressive behaviors are one, important, component. Some species such as mice are particularly opportunistic and may show rapid and dramatic changes in social structure in accord with habitat alterations (Bronson, 1979; Gray and Hurst, 1997), a flexibility that may stem in part from their long-term status as human commensals, with its strong requirement of rapid adjustment to host-initiated changes (Blanchard et al. in press). However, the ecological conditions under which most mammalian species have evolved are less variable than those associated with human habitations and human geographic movements, and the social systems evolving in most habitats appear also to be more conservative and resistant to change than are those of mice.

Evaluation of the rate of change in evolved characteristics of animals in response to important alterations in ecological conditions constitutes a difficult field of study, but some estimates may be obtained when a fossil record is available that permits information on relatively specific ecological changes. For example, it has been estimated that reductions in selective behavioral responsivity to rattlesnakes and in resistance to the venom of these snakes by California ground squirrels both decline over periods measured in the tens of thousands of years after rattlesnakes have disappeared from the squirrels' habitats (Coss et al., 1993). As this example suggests, when ecological changes make some of the existing characteristics of species less adaptive than previously, the replacement of these by more adaptive characteristics can be a lengthy and variable process; moreover, maladaptive as well as adaptive aspects of the emerging behaviors may be relevant to the patterns that ultimately emerge.

With complex behavior patterns such as those involved in social relationships an even longer time-frame might be needed than for venom resistance and other purely physiological adaptations. However, following long-term exposure to diverse situations, even closely related species would be expected to show behavioral differences based on what is most adaptive in their particular habitats: Rubenstein (2009, p. 243) gives the example of plains 
zebras (Equus burchelli), living in an environment in which close proximity of food and water allow female zebras to consistently form groups, in turn permitting males to vie for harems in this home range. In contrast, Grevy's zebra (Equus grevyi) inhabit locales where food and water are widely dispersed and scarcer, such that females forage alone and must travel between feeding and watering areas. In this species males form territories along the traveling routes, gaining breeding access to females that pass through or linger within the territory. In both the harem and territorial social systems, zebra males attempt to control access to females in breeding condition, but the time-frame and the location of these efforts vary with the conditions under which these animals have evolved.

\section{A PARTICULAR CASE IN POINT: FELIDS}

Some of these considerations may be relevant to a question that was raised at the very beginning of the scientific study of the evolution of behavior (Darwin, 1871): What is the basis for the evolution of the lion's mane? Is this related to the social systems of lions, which are unique among felids?

There are about 40 species of felids, all stemming from a split from other stem-line carnivores about 10-15 million years ago (mya). Animals that can be identified with existing species emerged over a period from about 10-12 mya (for ocelots) to very recently, possibly within historic times. Felids range in size from the blackfooted cat (about $3 \mathrm{lbs}$ ) to the Siberian tiger, weighing about 200x more, and are world-wide in distribution, excepting only Antarctica and most remote islands. Felid social systems are relatively similar across species: Adult animals tend to be solitary except for females and their young, and amicable adult encounters tend to be connected with reproduction.

A great deal is known of the specifics of aggression in Felids, due in large part to the work of Paul Leyhausen, who worked with domesticated cats and with other felid species in captivity, at the Max Planck Institute for Behavioral Physiology, at Wuppertal. Large felids, of the genus Panthera have also been the subjects of extensive field work, which has generally affirmed Leyhausen's conclusions about conservation of many aggressive behaviors and facial expressions across felid species. Briefly, Leyhausen (1978) described intraspecific aggression in these animals as a behavior that is capable of producing great damage, as all felids have weapon systems that have evolved to facilitate their roles as predators but are used also in within-species fighting. Leyhausen also indicated that aggression in felids is more regulated by effective defenses than responsive to the submission signals that are quite effective in reducing intra-group fighting in many canid species, such as wolves and dogs. By selecting animals and arranging situations, Leyhausen was able to polarize attack and defensive behaviors in domesticated cat subjects, or, alternatively, to maximize attack motivations for both combatants. In a highly polarized attackdefend situation, the attacker stands tall and advances directly toward the victim while emitting low growls. The defending animal crouches down, or, with a mixture of aggressive and fearful motives, may assume the classic "Halloween cat" stance with arched back, and erected hairs. As the attacker approaches contact, the defending animal may assume a contorted posture, half on its back but facing the other cat, enabling both fore- and hindpaws to be drawn up and opposed to the oncoming attacker. This stance conceals the nape, the major target site for intraspecific offensive attack. Both fore- and hindpaws may lash out at the attacker and disembowelment of the attacker is possible, particularly if it attempts to reach over to bite at the partly supine defender's nape. However, when both animals are highly motivated to attack, a frontal approach is typically utilized by both, resulting in animals facing each other and delivering forepaw blows largely toward the head and neck of the other.

Cat social systems provide a strong enabling factor in the dangerousness of aggression in these animals. Because of their solitary life-style, there is little reason for a felid under attack from a member of its own species to stay and receive bites and blows from the highly developed weapon systems that are characteristic of all felid species. The only context in which fighting may be strongly adaptive is mating, where flight, even if successful in avoiding injury, results in a substantial reduction in a male's extended reproductive fitness. Given that felids, particularly the larger ones such as tigers and leopards, kill large prey, it might be assumed that fighting over such prey would constitute a frequent occasion for fighting. However, the solitary life-style of these animals also acts to reduce conspecific encounters over prey.

\section{LION SOCIAL SYSTEMS}

Lions are a different story. First, with the exception of the domesticated cat, which is not yet a truly separate species as it still freely interbreeds to produce fertile offspring with its wild ancestors (Driscoll et al., 2007), the lion (Panthera leo) is the most recent cat species to emerge. While the earliest lion-like cat may date to the late Pliocene, cave paintings indicate that males had no manes (Barnett et al., 2006). Modern maned lions appear to have descended from a single population that arose about 200 thousand years ago, possibly in Africa, and spread throughout the northern hemisphere, replacing earlier lion-like cats in Europe as recently as 10-15,000 years ago (Yamaguchi et al., 2004). Although Yamaguchi et al. (2004) suggest, based on a comparative analysis of food abundance factors in living species, that the earlier Holartic cave lion might have been group-living as are modern lions, there is no direct evidence that this was the case. Thus this particular mode of sociality, highly unusual for felids, may have been characteristic of Holarctic lions (Panthera leo spelaea) or, it may have evolved, along with the male lion's mane, only in modern lions.

The classic hypothesis for a relationship between group-living and the development of manes is that manes reduce the dangers associated with fighting within lion groups (Darwin, 1871; Ewer, 1968; Schaller, 1972; Blanchard and Blanchard, 1984). Insofar as group-living is adaptive, serious injuries resulting from fighting within the group would be maladaptive for both the attacker and the injured animal, encouraging the latter to leave the group or reducing its ability to join in protecting the group from attack by outsiders. This is a particularly important consideration for lions, in that take-over of prides by nomadic lions entails infanticide by the new pride males (Loveridge et al., 2006) providing an extremely direct and strong adaptive consequence for success or failure at take-over, which in turn reflects the strength and numbers of the male cohorts on each side of the battle. 
A recent proliferation of nature documentaries plus the development of YouTube and other online sources has made videos of fighting in a variety of animals available. There are literally dozens of lion fighting videos online, and some of these provide clear footage of adult males fighting, with continuity, in nonenclosed areas that appear to be the animals' natural habitats. Although the films were certainly selected for dramatic impact, and it is sometimes difficult to ascertain whether any external provocation might have been involved, it seems highly unlikely that the animals' actual fighting behaviors were trained or shaped. Moreover, a variety of animals and videotaping sources appear to have been involved, substantially reducing the possibility that the clips present a systematically biased view of the actual behaviors involved in serious fights in lions.

The form of both attack and defense in male lions appears to be highly consistent across these clips, particularly demonstrating the mutual frontal attack seen in other felids ${ }^{1}$. The only time that an attacked male voluntarily exposes its back to an attacker is when it is fleeing. Even then, as the pursuer comes close, the pursued animal typically turns toward it, presenting its own weapons. Even a young cub, attacked and ultimately killed by an adult male, turns to face its attacker, flipping on its back in a move reminiscent of defensive domestic cats, as contact becomes imminent ${ }^{2}$.

\section{ARGUMENTS AGAINST THE MANE AS PROTECTION}

This view of male lions' manes as protective has recently been challenged by findings regarding wound locations on wild males, females, and young; by studies measuring approaches to dummy male lions with varying mane characteristics; and by observations of maneless lions in the Tsavo area of Kenya. With reference to the first of these, West and Packer (2002) examined sites of "lioninflicted wounds" on a large sample of lions, sorting them into four regions; neck/shoulder, as delineated by the perimeter of the mane; face; trunk; and legs. They found that wounds were fairly evenly distributed over all four regions in females and subadults, and over three, excluding the area covered by the mane, in adult males. Moreover, females and subadults were equally likely to survive wounds to each body part. These figures are not easy to reconcile with those of Schaller (1972) who describes three direct observations of lions killing lions (p. 189): Of these, two involved bites to the nape of the neck, while the third was a bite to the lower back, severing the vertebral column. A fourth example, not witnessed but examined while the victim was still alive, albeit expiring, involved a pride male with multiple deep wounds, including a broken saggital crest, and a penetrating wound to the chest, with tatters of his mane scattered over a $3 \times 10$ meter area (p. 48). These examples do not indicate that other sites are not involved in attacks of one lion on another, but they do suggest that bites to the head and nape, if they reach these targets, are likely to be especially lethal. Moreover, in 259 observations of aggressive acts between female lions and cubs at kills, about $75 \%$ involved slaps at the head and neck, suggesting that these are indeed targets, albeit of blows that appear less likely to leave wounds (Schaller, 1972, p. 134).

${ }^{1} \mathrm{http}: / /$ www.youtube.com/watch?v $=$ XV4AIG7WPBo\&feature = related ${ }^{2}$ http://www.youtube.com/watch? $\mathrm{v}=\mathrm{VNiOkWcvc18 \& NR}=1$
It might also be noted that wound sites do not necessarily have the same meaning as do targets: If, as in domestic cats, female and subadult lions have behavioral defenses that serve to protect the neck and shoulder by interposing teeth and claws to the attacker, a lack of disproportionate wounds on these sites may simply reflect the success of such defenses. Indeed, if the face (one of the four areas measured) had a relatively even share of wounds (West and Packer, 2002) even though it is much the smallest of the four areas evaluated, this may suggest that faces were wounded disproportionately to their area, perhaps in consequence of a facing defense that served to protect the neck and shoulders. Our own observations of adult male lions suggest that facial wounds are very common (see Figure 1). At any rate, the argument that a lion's mane is protective applies to animals that have manes, i.e. adult males. If such protection were equally important for females and subadult males, and this was indeed the basis on which manes have evolved, then presumably females and subadult males would have manes as well. They do not.

A second finding relates to approach and avoidance responses of wild lions to dummies set up to have long or short manes, and, light or dark manes. Females approached the dark-maned model, and the long-maned model, proportionately more than did males (West and Packer, 2002). Female choice of both is consonant with findings that dark-maned males have higher testosterone levels than light-maned males, and that mane length (and other aspects of quality) reflect health as well as genetic differences. Male avoidance of these particular dummies may well reflect the same factors, and is also consonant with a view that mane quality provides protection against attack, providing abundantly maned lions an advantage in agonistic situations.

\section{SOCIALITY IN MANELESS LIONS}

A particularly interesting factor in the relationship between lion manes and lion social systems is that there are two groups of lions in which males show much less abundant manes; Asian lions in the Gir forest of India, and the Tsavo lions of lowland Kenya. Due to human pressures on their habitat, the Gir lions are basically a remnant population, albeit with relatively high genetic diversity (Sachdev et al., 2005) but the Tsavo lions are doing well, and lack of a mane does not appear to have had any effect upon their reproductive efficiency (Gnoske et al., 2006), or on their predatory capacity: Two of these male lions were notorious for killing over 100 workers on the Kenya-Uganda railway, at the end of the $19^{\text {th }}$ century (Patterson, 2004). Gir lions have substantially scantier manes than those in Africa, with the exception of the Tsavo region, while the Tsavo lions are typically characterized as maneless.

Abundantly-maned male lions disproportionately overheat when the ambient temperature is high (West and Packer, 2002), strongly suggesting that the relatively poor manes of lions in both areas constitutes a direct evolutionary response to the heat-based maladaptiveness of manes in these local climates. Tsavo, lying between the upland plateau of Kenya and the coast, is within three degrees of the equator and has no cool months of the year. The Gir forest has year-round high levels of both heat and humidity, producing a climate where "discomfort from heat and humidity" is rated as high or extreme for 10 of the 12 months of the year (BBC weather service). These climate factors, taken in conjunction with 
direct measures of overheating of lions with manes in hot weather, appear to provide a sufficient and direct explanation for the manelessness of Tsavo and Gir males.

If lion manes arise because they serve as a permissive factor in the context of multi-male prides, what happens to multi-male prides when males do not have manes? In particular, if mane reduction in these lions is an evolutionary response to long-term high heat and humidity in the environment, alterations in their social systems may be secondary to such male mane changes, i.e. represent an effect of mane changes on sociality.

Surveying 13 lion groups of known age and sexual composition in Tsavo, Kays and Patterson (2002) reported that only 2 of the 13 groups had more than one male, and both of these were nomadic, male-only groups. Moreover, in only one of the two were the animals adults. The male-female prides surveyed had an average of more than seven females each, indicating that resource scarcity was not important in group size, and could not account for the presence of only a single male per group.

These demographics constitute a very striking difference from lion prides in other areas of Africa. Schaller (1972; Table II) notes that in 14 Serengeti lion prides, there were between two and four adult males each, with no pride having only a single adult male. Schaller did not quantify mane characteristics in these males. However, in the Kays and Patterson (2002) study, mane scores based on length, thickness, and color of hair were determined for males of four prides and three nomad groups. Mean scores were somewhat higher for the pride males than for the nomad groups, with the latter containing a higher proportion of young males. However, these scores overlapped completely, ranging from 0 to 24 for the pride males and 0 to 24 for the nomad group males, suggesting that female choice based on male mane characteristics was not a major factor in the composition of prides. While this finding may seem somewhat at variance with West and Packer's (2002) finding that females tended to approach male dummies with darker/longer manes, it emphasizes that the motivations involved in such approaches are not clear. The appearance of a strange male in a female's pride territory may well elicit approaches based on motivations other than sexual interest (e.g. Schaller, 1972, p. 53), including assessment of the risk posed to herself and her offspring.

The Gir lions show an even more deviant pattern of sociality, compared to those in most areas of Africa. In the Gir forest "..male and female lions lead separate lives and rarely associate with each other... Prides are composed of related females, their young, and subadult male offspring..." (Sunquist and Sunquist, 2002, p. 293). Thus in both Tsavo and Gir, the scantiness or lack of manes in male lions is associated with a particular change in sociality, in which adult males do not simultaneously associate with both females and each other. Notably, the difference does not involve a reduction in association with females per se, as the Tsavo lion prides typically include one male and several females, nor does it involve a lack of male associations, as both Tsavo and Gir males often associate in male-only groups. The crucial feature appears to be whether multiple males and females associate in relatively long-term relationships, i.e. prides.

In the areas where they occur, these prides are crucially involved in successful lion reproduction. In Kruger, Smuts (1982) noted that prides without males in constant attendance failed to raise any cubs. As females are the primary hunters in most prides (Schaller, 1972), this failure to rear cubs probably is not due to cub starvation in prides without males, but instead is the consequence of infanticide by nomadic males (Bertram, 1978; Packer and Pusey, 1983). This suggests that multi-male, mixed-sex lion prides enhance reproductive success by protecting the pride from take-over and subsequent infanticide by other males.

If this analysis is valid, the adaptiveness of male manes may be to allow males within prides to fight, while reducing the chance of lethal contact with the particularly vulnerable sites that are normally protected by the mane. There is some difference of opinion (or observation) about the levels of aggression by male lions in a courtship context, with some authorities reporting vigorous fighting (Guggisberg, 1961) while others (Schaller, 1972) do not. Insofar as success in male-male fighting influences access to females in estrus, the male mane would have an obvious adaptive advantage in this context. However, fighting in contexts other than mating can also provide an arena for realization of the adaptiveness of manes in pride males. In particular, lions show little restraint of aggression when feeding, showing few inhibitions about slashing and biting fellow pride members: Schaller (1972; p. 135) suggests that this is due to their lack of a true dominance hierarchy, related to the generally solitary life-styles of felids.

There is no reason to believe that such disputes are less common, or potentially less damaging, in male-male groups. However, if fighting within a nomadic multi-male group is sufficiently damaging as to injure or drive away group members, this has little or no immediate impact on the reproductive success of males in the group, although it might reduce the probability of future success in taking over a pride. In contrast, for a pride male to be injured or driven off makes the pride immediately and substantially more vulnerable, and the infanticide that typically follows a successful take-over may completely eliminate the progeny of the pride males (Packer et al., 2009).

So, to go back to the question posed in the introduction to this article, is it male-male fighting, or female choice, or both, that makes the lion's mane adaptive? In favor of a view that male-male contests are made more adaptive by manes are findings that:

(1) Fatal injuries from lion fights often involve the head and nape.

(a) There is some evidence for targeting of these sites.

(b) Lion fighting involves frontal confrontations such that damage in these areas might be expected in the absence of evolved targeting and

(c) These areas are particularly vulnerable, in terms of immediate mortality in response to bites and blows.

(2) When manes are reduced, likely by environmental factors, multi-male, mixed-sex prides are vanishingly rare.

The West and Packer (2002) findings do suggest some female choice of more abundantly maned males, in that:

(1) Females approached heavily-maned dummies more than did males.

(2) Also, field studies indicate that female lions do exercise a substantial degree of mate choice, although it is not known if this reflects male mane characteristics.

(3) Mane quality is a sensitive index of health in lions. 
Putting these findings together, it seems most like that "both" is the best answer, but with the further provision that female choice appears to be based on a characteristic that is independently adaptive in terms of the social characteristics of most lions. That is, the mane "honestly advertises" the quality of a trait that is adaptive for males (see Johnstone, 1995 for a discussion of this view of sexual section). Indeed, if the mane were selected simply on the basis of female choice, albeit with the result that male offspring with high levels of this trait would similarly prove attractive to females, this would raise a legitimate issue of why only female lions, of all the many felid species, show such a choice. The relationship between multi-male mixed-sex social groups and male manes might conceivably have arisen as a coincidence. However, the "coincidence" explanation is substantially challenged by findings that mane reductions in the Gir and Tsavo lions, that appear to be the result of persistent hot or hot and humid environments known to produce overheating in maned lions, are associated with a virtual elimination of multi-male prides.

\section{LIONS....AND MEN?}

Humans are fascinated with lion manes. This may reflect nothing more than a human propensity to be intrigued by unique or unusual features of the natural world. It is possible, however, that something more is involved. The lion's mane is a highly unusual, sexually dimorphic, male feature, arising about the time of puberty, found in a species that is more social than are its phylogenetic relatives, and in possession of weapons that may be lethally applied to others of its kind: The feature covers an area that is directly accessible in frontal confrontations, may be a particular target of attacks, and is highly vulnerable, as indexed by potential mortality when wounded.

Morris (1968), in "The Naked Ape" raised the intriguing question of why humans have less, or shorter and thinner, hair on most body sites. Perhaps an even more intriguing question is why humans, absolutely uniquely in the animal kingdom, have two sexually dimorphic hair patches that grow indefinitely. Moreover, one of these patches, the beard, begins to grow during puberty, and is thickest in young adulthood and full maturity, tending to decline in old age.

Like the lion's mane, male beards are widely assumed to be somewhat adaptive in the context of providing a visual aid to identification of gender at a distance; in advertising social dominance; or as sexually attractive to women (Barber, 1995). As evidence for the latter is inconsistent (Feinman and Gill, 1977; Hatfield and Sprecher, 1986), and the accuracy and value of other presumed adaptive functions of beards are debatable (Barber, 1995), the near-universal existence of male beards in humans, albeit variable in individual magnitude, remains something of a mystery.

What about a protective function, similar to that of the lion's mane? Figure 1 provides a very good look at the facial and neck structures covered by beards, as well as some estimation of the degree of coverage they may confer. These areas are front and center in aggressive confrontations and may be especially vulnerable to blows when weapons are not used, or to blows from the "blunt force" weapons that have been available throughout much of hominid evolution. The "glass chin" phenomenon is well known in boxing, and direct blows to the front and sides of the neck as

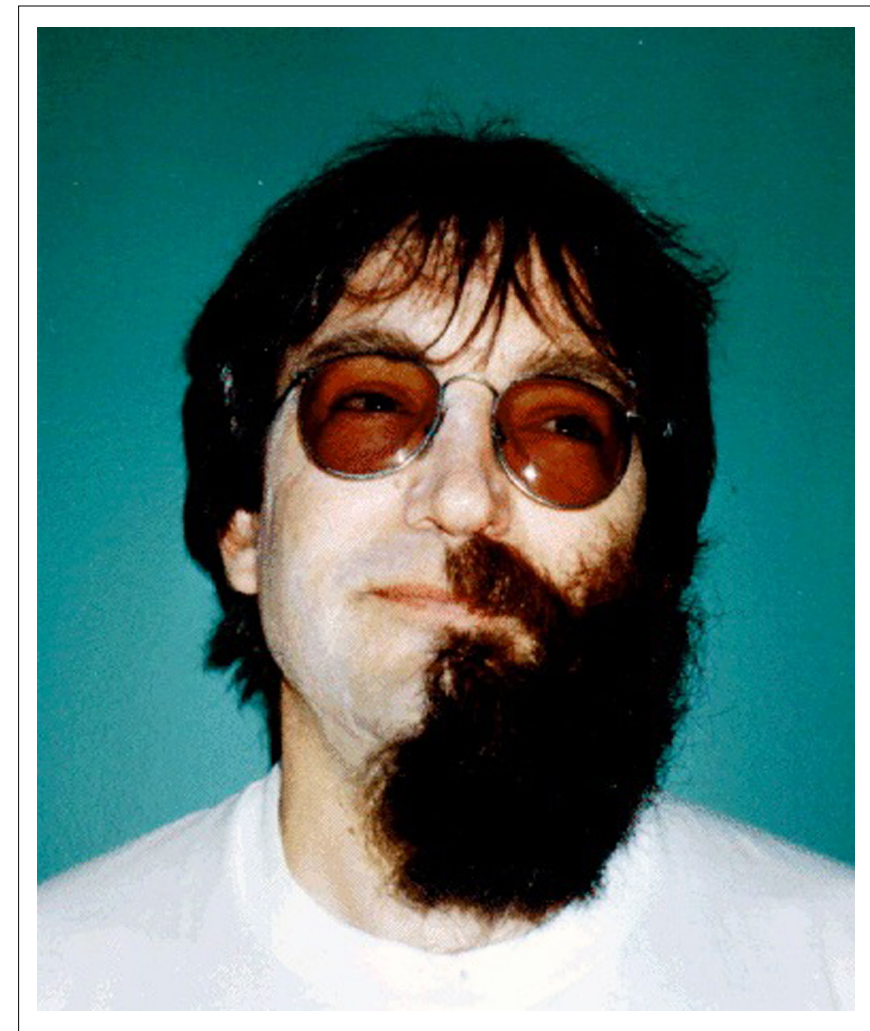

FIGURE 1 |Adult male with one half of his beard removed.

well as the area just under the nose can be particularly lethal. Both are particular targets of attack in unarmed combat techniques (Schillingford, 2001). This protective feature of human beards is also recognized in the Technical and Competition Rules of the international Amateur Boxing Association, which prohibit beards in boxing matches ${ }^{3}$.

In addition, based on extensive observations of encounters in young children, the child psychologist Margaret Manning has suggested (personal communication) that the head/face/neck area is a specific target of attack in young children. This is particularly interesting as combat training is unlikely to be involved in childrens' preferences, and it may provide something of a functional or adaptive basis for the nonsexually dimorphic, evergrowing hair patch that covers the dorsal, side, and back sections of the head. Notably, if left to grow, head hair also covers the back and sides of the neck, leaving the front of the neck, the most vulnerable aspect in frontal confrontations, exposed except in pubertal and postpubertal males.

The many points where manes and beards show parallels also bring up the interesting question of why other mammalian species with potentially lethal weaponry fail to develop such protections. One answer, already mentioned, is that they may be much less necessary in species with solitary life-styles. Another is that a structure such as the horns or antlers of ungulates may simultaneously serve as weapon, target site, and protection against this specialized

${ }^{3}$ http://www.aiba.org/documents/site1/Articles\%20\&\%20Rules/2008/technical_ and_competition_rules_e.pdf) 
form of intraspecific attack. Indeed, such "protective" weaponry is much more common in gregarious than in solitary species of African bovids (Estes, 1992). However, many other social species have weapons that are clearly capable of causing lethal conspecific damage, but have no notable structures to protect highly vulnerable sites.

One possible reason for this omission may be that animals with both dangerous weapons and a long and consistent evolutionary history of sociality, such as most canids, tend to have a clearer within-group dominance structure than do lions, including behavior mechanisms ("submission") that reduce intraspecific attack (MacDonald and Sillero-Zubiri, 2004). Humans do certainly have both dominance hierarchies and submissive behaviors, but these appear to vary widely across cultures and their existence and extent in precultural humans is difficult to estimate. While there appears to be a linear dominance hierarchy in male chimpanzees (Goldberg and Wrangham, 1997), this appears not to be so in bonobos (Paoli et al., 2006); these having equal claim to the ancestral line from which humans split. Perhaps lions and humans came to their need

\section{REFERENCES}

Arakawa,H.,Arakawa,K.,Blanchard, D. C., and Blanchard R. J. (2009). Social features of scent-donor mice modulate scent marking of C57BL/6J recipient males. Behav. Brain Res. 14, 138-145.

Barber, N. (1995). The evolutionary psychology of physical attractiveness: Sexual selection and human morphology. Ethol. Sociobiol. 16, 395-424.

Barnett, R., Yamaguchi, N., Barnes, I., and Cooper, A. (2006). The origin, current diversity and future conservation of the modern lion (Panthera leo). Proc. Biol. Sci. 273, 2119-2125.

Bertram, B. C. R. (1978). Pride of Lions. Osceola, WI, Voyageur Press.

Blanchard, D. C., Arakawa, H., Crawley, J. N., and Blanchard, R. J. (In Press). Social behaviors in wild and laboratory mice with a special emphasis on the C57BL/6J inbred strain. In Handbook of Behavioral Genetics of the Mouse, W. E. Crusio, F. L. Slyter and R. T. Gerlai, eds (Amsterdam, Elsevier).

Blanchard, R. J., and Blanchard, D. C. (eds) (1984). Advances in the Study of Aggression, Vol. I. New York, Academic Press.

Bronson, F. H. (1979). The reproductive ecology of the house mouse. Q. Rev. Biol. 54, 265-299.

Coss, R. G., Guse, K. L., and Poran, N. S. (1993). Development of antisnake defenses in California ground squirrels (Spermophilus beecheyi): II. Microevolutionary effects of relaxed selection from rattlesnakes. Behaviour 124, 137-164.

Darwin, C. (1871). The Descent of Man. New York, Prometheus Books.
Driscoll, C. A, Menotti-Raymond, M., Roca, A. L., Hupe, K., Johnson, W. E., Geffen, E., Harley, E. H., Delibes, M., Pontier, D., Kitchener, A. C., Yamaguchi, N., O'brien, S. J., and Macdonald, D. W. (2007). The Near Eastern origin of cat domestication. Science 317, 519-523.

Estes, R. (1992). Behavior Guide to African Mammals. Berkeley, Univ. of California Press.

Ewer, R. F. (1968). Ethology of Mammals. New York, Plenum.

Feinman, S., and Gill, G. W. (1977). Females' responses to males' beardedness. Percept. Mot. Skills 44, 533-534.

Gnoske, T. P., Celesia, G. G., and Kerbis Peterhans, J. C. (2006). Dissociation between mane development and sexual maturity in lions (Panthera leo): solution to the Tsavo riddle? J. Zool. 270, 551-560.

Goldberg, T. L., and Wrangham R. W. (1997). Genetic correlates of social behaviour in wild chimpanzees: evidence from mitochondrial DNA. Anim. Behav. 54, 559-570.

Gray, S. J., and Hurst, J. L. (1997). Behavioural mechanisms underlying Mus domesticus and grassland Mus spretus. Anim. Behav. 53, 511-524.

Guggisberg, C. (1961).Simba. Capetown, Howard Timmins.

Hatfield, E., and Sprecher, S. (1986). Mirror, Mirror... The Importance of Looks in Everyday Life. Albany, NY, State University of New York Press.

International Boxing Association (n.d.). Technical and Competition Rules. Available at: http://www.aiba.org/documents/site1/Articles\%20\&\%20Rule the spatial dispersion of commensal

for protection against lethal intraspecific attack through slightly different routes; Lions with long-term lethal weapons but lately evolving a social life-style, whereas people are from a line with substantial, though not clearly delineated, sociality, but lately evolving the development and use of lethal weapons. Both species may have encountered the combination of a social life-style and lethal weaponry too rapidly to evolve innately-organized social mechanisms that protect individuals from the damaging consequences of intra-group attack.

This view implies that structural protections; here, long, coarse, and abundant hair growth in relevant sites, may be more easily or rapidly evolved than are complex behavioral changes. Such an issue may be resolvable, given current developments in molecular genetics. However, it is only one of many potential questions following from the present analysis. It seems likely that a combination of experimental and ethological approaches may be necessary in order to gain a better understanding of the complex evolutionary interplay between sociality and other behavioral and structural characteristics of particular species.

s/2008/technical_and_competition_ rules_e.pdf

Johnstone, R. A. (1995). Sexual selection, honest advertisement and the handicap principle: reviewing the evidence. Biol. Rev. Camb. Philos. Soc. 70, 1-65.

Kays, R. W., and Patterson, B. D. (2002). Mane variation in African lions and its social correlates. Can. J. Zool. 80, 471-478.

Leyhausen, P. (1978). Cat Behaviour: The predatory and Social Behaviour of Domestic and Wild Cats. London, Garland STM Press.

Loveridge, A. J., Searle, A. W., and Murindagomo, F. (2006). The impact of sport-hunting on the population dynamics of an African lion population in a protected area. Biol. Conserv. 134, 548-558.

MacDonald, D. W., and Sillero-Zubiri, C. (2004). The Biology and Conservation of Wild Canids. Oxford, Oxford University Press.

Malmqvist, B. (1983). Breeding behavior of Brook Lampreys Lampetra-planeri experiments on mate choice. Oikos 41 , 43-48.

Morris, D. (1968). The Naked Ape. New York, McGraw-Hill.

Moynihan, M. H. (1998). The Social Regulation of Competition and Aggression in Animals. Washington, Smithsonian Institution Press.

Packer, C., Kosmala, M., Cooley, H. S., Brink, H., Pintea, L., Garshelis, D., Purchase, G., Strauss, M., Swanson, A., Balme, G., Hunter, L., and Nowell, K. (2009).Sporthunting, predator control and conservation of large carnivores. PLoS ONE 4, e5941. doi:10.1371/journal.pone.0005941.
Packer, C., and Pusey, A. (1983). Adaptations of female lions to infanticide by incoming males. Am. Nat. 121, 716-728.

Paoli, T., Palagi, E., and Tarli, S. M. (2006). Reevaluation of dominance hierarchy in bonobos (Pan paniscus). Am. J. Phys Anthropol. 130, 116-122.

Patterson, B. D. (2004). The Lions of Tsavo: Exploring the Legacy of Africa's Notorious Man-Eaters. New York, McGraw-Hill.

Rubenstein, D. I. (2009). Social behavior and sociobiology. In Evolution: The first four billion years, M. Ruse and J. Travis, eds (Cambridge, MA, Harvard University Press), pp. 237-255.

Sachdev, M., Sankaranarayanan, R., and Reddanna, P. (2005). Major histocompatibility complex class I polymorphism in Asiatic lions. Tissue Antigens 66, 9-18.

Schaller, G. B. (1972). The Serengeti Lion A Study of Predator-Prey Relations. Chicago, University of Chicago Press.

Schillingford, R. (2001). The Elite Forces Handbook of Unarmed Combat. New York, St. Martins Griffin.

Smuts, G. L. (1982). Lion. South Africa, Macmillan South Africa Publishers Ltd.

Sunquist, M. E., and Sunquist, F.C. (2002). Wild Cats of the World. Chicago, Univ. Chicago Press.

West, P. M., and Packer, C. (2002). Sexual selection, temperature, and the lion's mane. Science 297, 1339-1343.

Wilson, E. O. (1971). Sociobiology: The New Synthesis. Cambridge, MA, Harvard University Press. 
Yamaguchi, N., Cooper, A., and Werdelin, L. (2004). Evolution of the mane and group-living in the lion (Panthera leo) a review. J. Zool. 263, 329-342.

Conflict of Interest Statement: The authors declare that the research was conducted in the absence of any commercial or financial relationships that could be construed as a potential conflict of interest.

Received: 15 August 2009; paper pending published: 11 September 2009; accepted:
28 October 2009; published online: 20 January 2010.

Citation: Blanchard DC (2010) Of lion manes and human beards: some unusual effects of the interaction between aggression and sociality. Front. Behav. Neurosci. 3:45. doi: 10.3389/neuro.08.045.2009
Copyright (c) 2010 Blanchard. This is an open-access article subject to an exclusive license agreement between the authors and the Frontiers Research Foundation, which permits unrestricted use, distribution, and reproduction in any medium, provided the original authors and source are credited. 